\title{
Altered Expression of Endoplasmic Reticulum Stress-Related Genes in the Middle Frontal Cortex of Subjects with Autism Spectrum Disorder
}

\author{
Amanda Crider $^{\mathrm{a}}$ Anthony O. Ahmed ${ }^{\mathrm{b}}$ Anilkumar Pillai $^{\mathrm{a}}$ \\ ${ }^{a}$ Department of Psychiatry and Health Behavior, Augusta University, Augusta, GA, and ${ }^{\text {b}}$ Department of \\ Psychiatry, Weill Cornell Medical College, White Plains, NY, USA
}

\section{Keywords}

Endoplasmic reticulum stress · Autism spectrum disorder .

Cortex · Autism

\begin{abstract}
The endoplasmic reticulum (ER) is an important organelle responsible for the folding and sorting of proteins. Disturbances in ER homeostasis can trigger a cellular response known as the unfolded protein response, leading to accumulation of unfolded or misfolded proteins in the ER lumen called ER stress. A number of recent studies suggest that mutations in autism spectrum disorder (ASD)-susceptible synaptic genes induce ER stress. However, it is not known whether ER stressrelated genes are altered in the brain of ASD subjects. In the present study, we investigated the mRNA expression of ER stress-related genes (ATF4, ATF6, PERK, XBP1, sXBP1, CHOP, and IRE1) in the postmortem middle frontal gyrus of ASD and control subjects. RT-PCR analysis showed significant increases in the mRNA levels of ATF4, ATF6, PERK, XBP1, CHOP, and IRE1 in the middle frontal gyrus of ASD subjects. In addition, we found a significant positive association of mRNA levels of ER stress genes with the diagnostic score for stereotyped behavior in ASD subjects. These results, for the first time, provide the evidence of the dysregulation of ER stress genes in the brain of subjects with ASD.

๑) 2017 S. Karger AG, Basel
\end{abstract}

๑) 2017 S. Karger AG, Basel

\section{Introduction}

Autism spectrum disorder (ASD) is among the most devastating neurological disorders of childhood with a prevalence of about 1 in 68 children [1]. It is characterized by social interaction deficits, difficulties in both verbal and nonverbal communication, repetitive behaviors, and obsessive tendencies. In addition, neuroimaging studies have provided evidence for aberrant functional and structural connectivity between cortical regions in individuals with ASD [2,3]. While there is a clear genetic predisposition to ASD, known genetic variants can account for no more than $5-15 \%$ of all cases and there is emerging evidence that epigenetic factors also contribute to the molecular pathology of the illness $[4,5]$.

The endoplasmic reticulum (ER) is an important organelle responsible for the folding and sorting of proteins. Disturbances in redox or calcium homeostasis in the ER caused by pathophysiological or environmental stimuli can trigger a cellular response known as the unfolded protein response (UPR), leading to accumulation of unfolded or misfolded proteins in the ER lumen called ER stress [6]. Three ER-resident proteins have been identified as sensors of ER stress: IRE1 (inositol-requiring protein 1), PERK (PKR [double-stranded-RNA-dependent protein kinase]-like ER kinase), and ATF6 (activating transcrip-

\section{KARGER}

E-Mail karger@karger.com

www.karger.com/mnp
Anilkumar Pillai, $\mathrm{PhD}$

Department of Psychiatry and Health Behavior Medical College of Georgia, Augusta University 997 St. Sebastian Way, Augusta, GA 30912 (USA) E-Mail apillai@augusta.edu 
tion factor 6) [7, 8]. IRE1 is a type 1 transmembrane serine/threonine receptor protein kinase which functions as a sensor for misfolded/unfolded proteins in the ER lumen. Activated IRE1 induces the splicing of XBP1 (Xbox-binding protein 1) mRNA by cleaving off its intron $[9,10]$. PERK is a type 1 transmembrane protein kinase that transmits stress signals in response to the perturbation of protein folding [11]. When activated, PERK phosphorylates the a subunit of eIF2 (eukaryotic initiation factor 2) leading to the translation of ATF4 and activation of the CHOP promoter $[12,13]$. ER stress activates ATF6 by translocating it from the ER to Golgi complex, where it is cleaved by the Golgi-resident serine proteases S1P and S2P (site 1 and site 2 proteases, respectively) [14, 15] resulting in the activation of the transcription of UPR targets such as GRP78, CHOP, and XBP1 $[10,15,16]$. The UPR is generally a pro-survival mechanism, mediated by translation arrest and the induction of a number of transcription factors and chaperone proteins that function to restore ER homeostasis and help the cells adapt to ER stress conditions. However, when ER stress is prolonged or the degree of ER stress is too severe, UPR signaling can initiate programmed cell death by activating stress-induced proapoptotic factors $[17,18]$.

A number of recent studies have suggested an important role of ER stress in the pathophysiology of ASD [19, 20]. In particular, genetic variations in several synaptic genes implicated in ASD have been shown to induce ER stress genes. Overexpression of neuroligin (NLGN) 3 mutant has been shown to activate the UPR downstream of the stress sensors ATF6, IRE1, and PERK [21]. Mutated GPR85 resulted in ER stress and impaired dendrite formation of hippocampal neurons [22]. In addition, mutated cell adhesion molecule-1 (CADM1) as well as NLGN3 (R451C) have been shown to upregulate CHOP expression [23]. Furthermore, inherited genetic variants in autism-related CNTNAP2 show perturbed trafficking and ATF6 activation [24]. Although these studies are interesting, it is still not known whether ER stress genes are altered in the brain of ASD subjects. In the present study, we examined the gene expression of ATF4, ATF6, PERK, $\mathrm{XBP} 1, \mathrm{XXP} 1, \mathrm{CHOP}$, and IRE1 in the postmortem middle frontal gyrus of ASD and control subjects. A number of studies including previous reports from our laboratory have shown an important role of the middle frontal gyrus in the pathophysiology of ASD [25-30]. We hypothesized that the expression of ER stress-related genes is impaired in ASD.

\section{Methods}

Postmortem Samples

Postmortem tissues from the middle frontal gyrus of control $(n=12 ;$ male $/$ female $=11 / 1)$ and ASD $(n=13 ;$ male $/$ female $=13 / 0)$ subjects were obtained from the NICHD Brain and Tissue Bank for Developmental Disorders at the University of Maryland, Baltimore, MD, USA. Table 1 shows a detailed description of the demographics of samples. The individual scores for each of the symptomatic domains according to the Autism Diagnostic Interview-Revised (ADI$\mathrm{R})$ were obtained from the brain bank website. The information on ADI-R was available for 9 out of 13 subjects with ASD. We did not find any significant difference in confounding variables such as postmortem interval, refrigeration interval, age at death, RNA integrity, and brain $\mathrm{pH}$ between ASD and control subjects.

\section{Quantitative Reverse Transcriptase PCR}

RNA was purified using a commercially available kit (SV RNA Isolation, Promega, Madison, WI, USA). Quantitative reverse transcriptase PCR (qRT-PCR) was performed on a MasterCycler (Eppendorf, Hamburg, Germany) using a SuperScript III Platinum SYBR Green One-Step qRT-PCR kit (Invitrogen, Carlsbad, CA, USA). Gene-specific primers were synthesized by Integrated DNA Technologies. Primers used are given in online supplementary table S1 (see www.karger.com/doi/10.1159/000477212). Ct values of genes of interest were normalized to the mean of housekeeping genes, $18 \mathrm{~S}$ and $\beta$-actin.

\section{Statistics}

We used multivariate analysis of covariance (MANCOVA) to examine differences in the mRNA levels of ER stress genes in the postmortem samples of people with ASD relative to control samples including ATF4, ATF6, PERK, XBP1, sXBP1, CHOP, and IRE1. We examined group differences in mRNA levels while considering age, storage time, postmortem interval, $\mathrm{pH}$, and RNA integrity for inclusion as possible covariates in the MANCOVA. Following an initial evaluation of the covariates, age, storage time, and sample $\mathrm{pH}$ were retained as covariates given that they possessed at least small associations - correlations of 0.20 and higher - with one or more of the mRNA values. Partial eta-square $\left(\eta^{2}\right)$ was computed as a measure of effect size difference and $p$ values less than 0.05 were flagged as statistically significant. All analyses were performed using SPSS Statistics 20 software (IBM).

\section{Results and Discussion}

The postmortem sample included those of 13 individuals with an ASD and 12 unaffected controls. Age, storage time, RNA integrity, postmortem interval, and sample $\mathrm{pH}$ all produced at least small associations with one or more of the mRNA levels of ER stress genes and storage time often produced significant associations (Table 2). All five covariates were therefore evaluated in the overall multivariate model. None of the covariates achieved statistical significance in the prediction of the ER stress genes.
86

Mol Neuropsychiatry 2017;3:85-91

DOI: $10.1159 / 000477212$
Crider/Ahmed/Pillai 
Table 1. Comparison of autism spectrum disorder (ASD) and control samples

\begin{tabular}{lcccc}
\hline Covariate & ASD & Control & $F(1,23)$ & $p$ \\
\hline Age, years & $11.80(5.80)$ & $10.83(5.01)$ & 0.20 & $>0.05$ \\
Postmortem interval, $h$ & $19.00(10.01)$ & $14.50(8.17)$ & 1.50 & $>0.05$ \\
Storage time, days & $2,828.77(1,434.06)$ & $4,400.42(2,366.92)$ & 4.11 & $>0.05$ \\
Sample pH & $6.11(0.26)$ & $5.95(0.22)$ & 2.73 & $>0.05$ \\
RNA integrity & $6.84(1.92)$ & $5.81(2.48)$ & 1.36 & $>0.05$ \\
\hline
\end{tabular}

Data are presented as mean $(\mathrm{SD})$.

Table 2. Correlation between covariates and endoplasmic reticulum stress genes

\begin{tabular}{lrrrrrrr}
\hline & ATF4 & ATF6 & PERK & XBP1 & sXBP1 & CHOP & IRE1 \\
\hline Storage time & -0.215 & $-0.401^{*}$ & -0.322 & $-0.413^{*}$ & -0.366 & -0.295 & -0.357 \\
Sample pH & 0.263 & 0.300 & 0.308 & 0.284 & 0.365 & 0.337 & 0.335 \\
RNA integrity & 0.107 & 0.176 & 0.090 & 0.179 & 0.096 & 0.260 & 0.232 \\
Age & 0.393 & 0.250 & 0.282 & 0.353 & 0.184 & 0.237 & 0.295 \\
Postmortem interval & 0.173 & 0.202 & 0.116 & 0.166 & 0.286 & 0.167 & 0.273 \\
\hline
\end{tabular}

ATF4, activating transcription factor 4; ATF6, activating transcription factor 6; PERK, protein kinase-like endoplasmic reticulum kinase; XBP1, X-box protein 1; sXBP1, spliced X-box protein 1; CHOP, CCAATenhancer-binding protein homologous protein; IRE1, inositol-requiring enzyme $1 .{ }^{*} p<0.05$.

The full multivariate model, however, showed that ASD status was a significant predictor of mRNA levels of ER stress genes (Wilk's $\lambda=0.075, F(7,12)=21.00, p<$ $0.001, \eta_{\mathrm{p}}^{2}=0.925$, observed power $\left.=1.00\right)$. An examination of the univariate between-subject effects showed that ASD status was associated with a statistically significant increase in the mRNA levels of ATF4 (1.26-fold), ATF6 (1.15-fold), PERK (0.8-fold), XBP1 (0.75-fold), CHOP (2.5-fold), and IRE1 (1.56-fold) (Fig. 1). There was a trend toward significance in SXBP1 mRNA levels (1.1-fold increase; $p=0.06$ ) between control and ASD subjects (Fig. 1). Table 3 summarizes the association of ER stress genes with domains of the ADI-R. We found significant positive associations of ER stress genes with the stereotyped behavior domain of the ADI-R.

The current knowledge regarding the role of ER stress in the pathophysiology of ASD is mainly based on data from autism-associated mutations in synaptic genes such as NLGN3, CNTNAP2, and CADM1 [19-24]. Our data provide the first evidence of altered ER stress genes in the brain of ASD subjects. Cotranslational modifications, such as $\mathrm{N}$-linked glycosylation and formation of disulfide bonds, facilitate proper folding of nascent polypeptides in

Endoplasmic Reticulum Stress in Autism the ER. Glycosylation is of great physiological significance since changes in glycans significantly change the structure and function of polypeptide parts of glycoproteins [31]. Proper glycosylation of membrane receptors is critical for adaptive properties of the cell and affects communication between cells [32]. Altered glycosylation could contribute to the pathophysiology of ASD, and indeed a number of mutations in enzymes involved in glycosylation are found in people with autism [33].

We found significant increases in ATF4, ATF6, PERK, $\mathrm{XBP} 1, \mathrm{CHOP}$, and IRE1 mRNA levels in the middle frontal gyrus of ASD subjects. Among these molecules, $\mathrm{CHOP}$ is known to interact with the heterodimeric receptors $\mathrm{GABA}_{\mathrm{B} 1 \mathrm{a}} \mathrm{R} / \mathrm{GABA}_{\mathrm{B} 2} \mathrm{R}$ and inhibits the formation of heterodimeric complexes resulting in the intracellular accumulation and reduced cell surface expression of receptors [34]. Interestingly, decreased levels of $\mathrm{GABA}_{\mathrm{B} 1} \mathrm{R}$ and $\mathrm{GABA}_{\mathrm{B} 2} \mathrm{R}$ have been found in the brain of ASD subjects [35]. What are the downstream mechanism mediating ER stress-induced changes in central nervous system function? One potential mechanism is inflammation. Accumulating evidence suggest that pathways activated by the ER stress response induce inflammation. When activated,

Mol Neuropsychiatry 2017;3:85-91 87 
Fig. 1. Increase in mRNA levels of endoplasmic reticulum stress genes in the middle frontal gyrus of autism spectrum disorder (ASD) subjects. mRNA levels of endoplasmic reticulum stress genes were determined by qRT-PCR in the middle frontal gyrus of ASD $(n=13)$ and control $(n=12)$ subjects. The $\mathrm{Ct}$ values were normalized to the mean of $18 \mathrm{~S}$ and $\beta$-actin. a Activating transcription factor 4 (ATF4). b Activating transcription factor 6 (ATF6). c Protein kinase-like endoplasmic reticulum kinase (PERK). d X-box protein 1 (XBP1). e Spliced X-box protein 1 (sXBP1). f CCAAT-enhancer-binding protein homologous protein (CHOP). g Inositol-requiring enzyme 1 (IRE1). ${ }^{*} p<0.05,{ }^{* *} p<0.01$, and ${ }^{* * *} p<0.0001$ vs. controls.

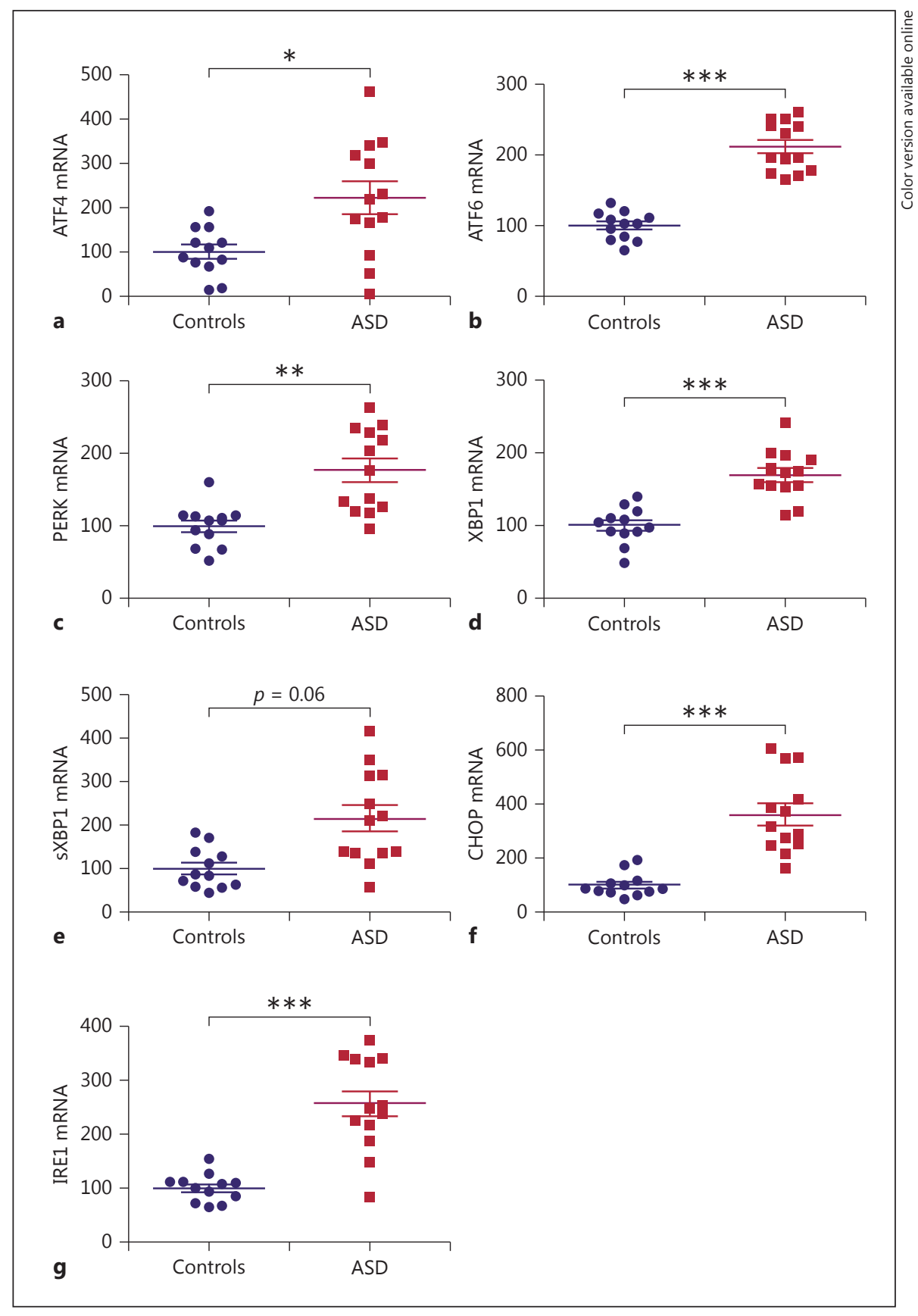

all three sensors of the UPR, PERK, IRE1, and ATF6, participate in upregulating inflammatory processes. It is known that PERK and IRE1 activation can interfere with NFKB inhibitory signals, thereby promoting a proinflammatory response [36]. In addition, $\mathrm{CHOP}$ has been shown to induce the expression of proinflammatory cytokines such as IL-23 [37]. Moreover, ER stress activates NLRP3 inflammasomes via thioredoxin-interacting protein
(TXNIP), leading to increases in proinflammatory cytokine levels $[38,39]$. In this regard, our earlier studies using the same tissue samples of the present study found increased levels of proinflammatory cytokines IL- $1 \beta$ and IFN- $\gamma$ in the middle frontal gyrus of ASD subjects [30].

Also, chronic ER stress is known to induce cellular apoptosis through a number of pathways including CHOP, calcium signaling, and microRNAs [40]. Activa- 
Table 3. Correlations of endoplasmic reticulum stress mRNAs with Autism Diagnostic Interview-Revised (ADI-R) scores

\begin{tabular}{lccccccc}
\hline & ATF4 & ATF6 & PERK & XBP1 & sXBP1 & CHOP & IRE1 \\
\hline ADI-R social interaction & 0.194 & 0.060 & -0.080 & 0.094 & 0.106 & -0.202 \\
ADI-R verbal communication & -0.056 & 0.126 & 0.394 & 0.143 & -0.328 & -0.309 & -0.063 \\
ADI-R nonverbal communication & -0.004 & 0.028 & -0.052 & -0.136 & -0.611 & -0.034 & -0.296 \\
ADI-R stereotyped behavior & 0.652 & $0.668^{*}$ & $0.762^{*}$ & $0.771^{*}$ & $0.719^{*}$ & $0.800^{*}$ & $0.702^{*}$ \\
ADI-R abnormalities in development & 0.355 & 0.207 & -0.033 & 0.208 & -0.197 & 0.002 & 0.230 \\
\hline
\end{tabular}

ATF4, activating transcription factor 4; ATF6, activating transcription factor 6; PERK, protein kinase-like endoplasmic reticulum kinase; XBP1, X-box protein 1; sXBP1, spliced X-box protein 1; CHOP, CCAAT-enhancer-binding protein homologous protein; IRE1, inositol-requiring enzyme $1 .{ }^{*} p<0.05$.

tion of PERK triggers a series of transcriptional responses mediated by ATF 4 and CHOP, which in turn inhibit the expression of anti-apoptotic protein $\mathrm{Bcl} 2$ and induce proapoptotic proteins such as $\mathrm{Bcl} 2$-interacting mediator of cell death (BIM) and p53 upregulated modulator of apoptosis (PUMA) [40]. The induction of pro-apoptotic signaling pathway results in the activation of BAX- and BAK-dependent apoptosis at the mitochondria and the activation of the caspase cascade [41]. Interestingly, decrease in $\mathrm{Bcl} 2$, but increase in $\mathrm{p} 53$ protein levels have been reported in the frontal cortex of ASD subjects [42].

We found that mRNA levels of ER stress genes are positively associated with the stereotyped behavior domain of the ADI-R. It has been shown that autism-associated mutations in NLGN3, which is known to induce ER stress, also increase stereotyped behavior in mice [43]. Similarly, mice lacking CNTNAP2 showed increased repetitive behaviors such as grooming and digging [44], further suggesting that abnormalities in ASD candidate genes implicated in ER stress induce stereotyped behavior in rodents. The present data was collected in a relatively small number of study subjects, which needs further investigation using larger samples before a conclusion can be drawn. Also, the change in gene expression as part of ER stress axis in ASD could be associated with other priming factors functional on different coordinates of this complex neurodevelopmental disorder. Additional studies are warranted to analyze the ER stress-inducing factors with direct relationship to the pathophysiological changes associated with ASD. To further establish a definitive role of ER stress in ASD pathophysiology, the following questions still need to be addressed: (1) Is ER stress in ASD of neurodevelopmental origin? (2) Are there factors other than mutant synaptic proteins that can trigger ER stress leading to ASD phenotype? (3) Is inflammation triggering ER stress or is ER stress triggering in-

Endoplasmic Reticulum Stress in Autism flammation leading to ASD phenotype? (4) Does ER stress induce changes in neural connectivity between key brain regions implicated in ASD pathophysiology? Future studies addressing the above questions might lead to a better understanding of the pathophysiology and provide new avenues of treatment of this disorder.

\section{Acknowledgements}

Human postmortem samples were obtained from the NICHD Brain and Tissue Bank for Developmental Disorders at the University of Maryland, Baltimore, MD, USA. The Bank is funded by NIH Contract No. \#HHSN275200900011C, Ref. No. NO1HD-9-0011. The authors would like to acknowledge the research support from US National Institute of Mental Health grant R01 MH 097060 (A.P.).

\section{Statement of Ethics}

The Augusta University Institutional Review Board has deemed this study exempt from full review due to the use of de-identified human postmortem brain samples, with no possibility to track back the identity of the donors. Human postmortem samples are from the NICHD Brain and Tissue Bank for Developmental Disorders at the University of Maryland with ethical permission granted by the institutional review boards of the University of Maryland.

\section{Disclosure Statement}

There are no conflicts of interest to report.
Mol Neuropsychiatry 2017;3:85-91 DOI: $10.1159 / 000477212$ 


\section{References}

1 Christensen DL, Baio J, Van Naarden Braun K, Bilder D, Charles J, Constantino JN, Daniels J, Durkin MS, Fitzgerald RT, KurziusSpencer M, Lee LC, Pettygrove S, Robinson C, Schulz E, Wells C, Wingate MS, Zahorodny W, Yeargin-Allsopp M; Centers for Disease Control and Prevention (CDC): Prevalence and Characteristics of Autism Spectrum Disorder Among Children Aged 8 Years - Autism and Developmental Disabilities Monitoring Network, 11 Sites, United States, 2012. MMWR Surveill Summ 2016;65:1-23.

2 Vissers ME, X Cohen M, Geurts HM: Brain connectivity and high functioning autism: a promising path of research that needs refined models, methodological convergence, and stronger behavioral links. Neurosci Biobehav Rev 2012;36:604-625.

3 Dichter GS: Functional magnetic resonance imaging of autism spectrum disorders. Dialogues Clin Neurosci 2012;14:319-351.

4 Huguet G, Ey E, Bourgeron T: The genetic landscapes of autism spectrum disorders. Annu Rev Genomics Hum Genet 2013;14: 191-213.

5 Cohen D, Pichard N, Tordjman S, Baumann C, Burglen L, Excoffier E, Lazar G, Mazet P, Pinquier C, Verloes A, Héron D: Specific genetic disorders and autism: clinical contribution towards their identification. J Autism Dev Disord 2005;35:103-116.

6 Zhang K, Kaufman RJ: Signaling the unfolded protein response from the endoplasmic reticulum. J Biol Chem 2004;279:25935-25938.

7 Schröder M, Kaufman RJ: ER stress and the unfolded protein response. Mutat Res 2005; 569:29-63.

8 Xu C, Bailly-Maitre B, Reed JC: Endoplasmic reticulum stress: cell life and death decisions. J Clin Invest 2005;115:2656-2664.

9 Calfon M, Zeng H, Urano F, Till JH, Hubbard SR, Harding HP, Clark SG, Ron D: IRE1 couples endoplasmic reticulum load to secretory capacity by processing the XBP- 1 mRNA. Nature 2002;415:92-96.

10 Yoshida H, Okada T, Haze K, Yanagi H, Yura T, Negishi M, Mori K: ATF6 activated by proteolysis binds in the presence of NF-Y (CBF) directly to the cis-acting element responsible for the mammalian unfolded protein response. Mol Cell Biol 2000;20:6755-6767.

11 Harding HP, Zhang Y, Ron D: Protein translation and folding are coupled by an endoplasmic-reticulum-resident kinase. Nature 1999;397:271-274.

12 Fawcett TW, Martindale JL, Guyton KZ, Hai T, Holbrook NJ: Complexes containing activating transcription factor (ATF)/cAMP-responsive-element-binding protein (CREB) interact with the CCAAT/enhancer-binding protein (C/EBP)-ATF composite site to regulate Gadd153 expression during the stress response. Biochem J 1999;339:135-141.
13 Harding HP, Zhang Y, Bertolotti A, Zeng H, Ron D: Perk is essential for translational regulation and cell survival during the unfolded protein response. Mol Cell 2000;5:897-904.

14 Shen J, Chen X, Hendershot L, Prywes R: ER stress regulation of ATF6 localization by dissociation of BiP/GRP78 binding and unmasking of Golgi localization signals. Dev Cell 2002;3:99-111.

15 Haze K, Yoshida H, Yanagi H, Yura T, Mori $\mathrm{K}$ : Mammalian transcription factor ATF6 is synthesized as a transmembrane protein and activated by proteolysis in response to endoplasmic reticulum stress. Mol Biol Cell 1999; 10:3787-3799.

16 Yoshida H, Haze K, Yanagi H, Yura T, Mori $\mathrm{K}$ : Identification of the cis-acting endoplasmic reticulum stress response element responsible for transcriptional induction of mammalian glucose-regulated proteins. Involvement of basic leucine zipper transcription factors. J Biol Chem 1998;273:3374133749 .

17 Lindholm D, Wootz H, Korhonen L: ER stress and neurodegenerative diseases. Cell Death Differ 2006;13:385-392.

18 Ai D, Baez JM, Jiang H, Conlon DM, Hernandez-Ono A, Frank-Kamenetsky M, Milstein S, Fitzgerald K, Murphy AJ, Woo CW, Strong A, Ginsberg HN, Tabas I, Rader DJ, Tall AR: Activation of ER stress and mTORC1 suppresses hepatic sortilin-1 levels in obese mice. J Clin Invest 2012;122:1677-1687.

19 Momoi T, Fujita E, Senoo H, Momoi M: Genetic factors and epigenetic factors for autism: endoplasmic reticulum stress and impaired synaptic function. Cell Biol Int 2010;34:1319.

20 Etherton M, Földy C, Sharma M, Tabuchi K, Liu X, Shamloo M, Malenka RC, Südhof TC: Autism-linked neuroligin-3 R451C mutation differentially alters hippocampal and cortical synaptic function. Proc Natl Acad Sci USA 2011;108:13764-13769.

21 Ulbrich L, Favaloro FL, Trobiani L, Marchetti V, Patel V, Pascucci T, Comoletti D, Marciniak SJ, De Jaco A: Autism-associated $\mathrm{R} 451 \mathrm{C}$ mutation in neuroligin3 leads to activation of the unfolded protein response in a PC12 Tet-On inducible system. Biochem J 2016;473:423-434.

22 Fujita-Jimbo E, Tanabe Y, Yu Z, Kojima K, Mori M, Li H, Iwamoto S, Yamagata T, Momoi MY, Momoi T: The association of GPR85 with PSD-95-neuroligin complex and autism spectrum disorder: a molecular analysis. Mol Autism 2015;6:17.

23 Fujita E, Dai H, Tanabe Y, Zhiling Y, Yamagata T, Miyakawa T, Tanokura M, Momoi MY, Momoi T: Autism spectrum disorder is related to endoplasmic reticulum stress induced by mutations in the synaptic cell adhesion molecule, CADM1. Cell Death Dis 2010; 1:e47.
24 Falivelli G, De Jaco A, Favaloro FL, Kim H, Wilson J, Dubi N, Ellisman MH, Abrahams BS, Taylor P, Comoletti D: Inherited genetic variants in autism-related CNTNAP2 show perturbed trafficking and ATF6 activation. Hum Mol Genet 2012;21:4761-4773.

25 Carper RA, Courchesne E: Localized enlargement of the frontal cortex in early autism. Biol Psychiatry 2005;57:126-133.

26 Barendse EM, Hendriks MP, Jansen JF, Backes WH, Hofman PA, Thoonen G, Kessels RP, Aldenkamp AP: Working memory deficits in high-functioning adolescents with autism spectrum disorders: neuropsychological and neuroimaging correlates. J Neurodev Disord 2013;5:14.

27 Zikopoulos B, Barbas H: Altered neural connectivity in excitatory and inhibitory cortical circuits in autism. Front Hum Neurosci 2013; 7:609.

28 Crider A, Pandya CD, Peter D, Ahmed AO, Pillai A: Ubiquitin-proteasome dependent degradation of GABAAal in autism spectrum disorder. Mol Autism 2012;5:45.

29 Crider A, Thakkar R, Ahmed AO, Pillai A: Dysregulation of estrogen receptor beta (ER $\beta)$, aromatase (CYP19A1), and ER co-activators in the middle frontal gyrus of autism spectrum disorder subjects. Mol Autism 2012;5:46.

30 Patel N, Crider A, Pandya CD, Ahmed AO, Pillai A: Altered mRNA levels of glucocorticoid receptor, mineralocorticoid receptor, and co-chaperones (FKBP5 and PTGES3) in the middle frontal gyrus of autism spectrum disorder subjects. Mol Neurobiol 2016;53: 2090-2099.

31 Skropeta D: The effect of individual N-glycans on enzyme activity. Bioorg Med Chem 2009; 17:2645-2653.

32 Dennis JW, Lau KS, Demetriou M, Nabi IR: Adaptive regulation at the cell surface by Nglycosylation. Traffic 2009;10:1569-1578.

33 van der Zwaag B, Franke L, Poot M, Hochstenbach R, Spierenburg HA, Vorstman JA, van Daalen E, de Jonge MV, Verbeek NE, Brilstra $E H$, van 't Slot R, Ophoff RA, van Es MA, Blauw HM, Veldink JH, Buizer-Voskamp JE, Beemer FA, van den Berg LH, Wijmenga $C$, van Amstel $H K$, van Engeland $H$, Burbach JP, Staal WG: Gene-network analysis identifies susceptibility genes related to glycobiology in autism. PLoS One 2009;4:e5324.

34 Sauter K, Grampp T, Fritschy JM, Kaupmann K, Bettler B, Mohler H, Benke D: Subtype-selective interaction with the transcription factor CCAAT/enhancer-binding protein $(\mathrm{C} /$ $\mathrm{EBP})$ homologous protein $(\mathrm{CHOP})$ regulates cell surface expression of $\mathrm{GABA}(\mathrm{B})$ receptors. J Biol Chem 2005;280:33566-33572.

35 Fatemi SH, Folsom TD, Reutiman TJ, Thuras PD: Expression of GABA(B) receptors is altered in brains of subjects with autism. Cerebellum 2009;8:64-69. 
36 Tam AB, Mercado EL, Hoffmann A, Niwa M: ER stress activates NF- $\kappa$ B by integrating functions of basal IKK activity, IRE1 and PERK. PLoS One 2012;7:e45078.

37 Ma Y, Brewer JW, Alan Diehl J, Hendershot LM: Two distinct stress signaling pathways converge upon the CHOP promoter during the mammalian unfolded protein response. J Mol Biol 2002;318:1351-1365.

38 Lerner AG, Upton JP, Praveen PV, Ghosh R, Nakagawa Y, Igbaria A, Shen S, Nguyen V, Backes BJ, Heiman M, Heintz N, Greengard P, Hui S, Tang Q, Trusina A, Oakes SA, Papa FR: IRE1 $\alpha$ induces thioredoxin-interacting protein to activate the NLRP3 inflammasome and promote programmed cell death under irremediable ER stress. Cell Metab 2012;16: 250-264.
39 Oslowski CM, Hara T, O’Sullivan-Murphy B, Kanekura K, Lu S, Hara M, Ishigaki S, Zhu LJ, Hayashi E, Hui ST, Greiner D, Kaufman RJ, Bortell R, Urano F: Thioredoxin-interacting protein mediates ER stress-induced $\beta$ cell death through initiation of the inflammasome. Cell Metab 2012;16:265-273.

40 Hetz C, Mollereau B: Disturbance of endoplasmic reticulum proteostasis in neurodegenerative diseases. Nat Rev Neurosci 2014; 15:233-249.

41 Scorrano L, Oakes SA, Opferman JT, Cheng EH, Sorcinelli MD, Pozzan T, Korsmeyer SJ: $\mathrm{BAX}$ and $\mathrm{BAK}$ regulation of endoplasmic reticulum $\mathrm{Ca} 2+$ : a control point for apoptosis Science 2003;300:135-139.
42 Araghi-Niknam M, Fatemi SH: Levels of Bcl2 and P53 are altered in superior frontal and cerebellar cortices of autistic subjects. Cell Mol Neurobiol 2003;23:945-952.

43 Rothwell PE, Fuccillo MV, Maxeiner S, Hayton SJ, Gokce O, Lim BK, Fowler SC, Malenka RC, Südhof TC: Autism-associated neuroligin-3 mutations commonly impair striatal circuits to boost repetitive behaviors. Cell 2014;158:198-212.

44 Peñagarikano O, Abrahams BS, Herman EI, Winden KD, Gdalyahu A, Dong H, Sonnenblick LI, Gruver R, Almajano J, Bragin A, Golshani P, Trachtenberg JT, Peles E, Geschwind DH: Absence of CNTNAP2 leads to epilepsy, neuronal migration abnormalities, and core autism-related deficits. Cell 2011;147:235246.

Endoplasmic Reticulum Stress in Autism 